\title{
Common childhood symptoms and rural home-treatment practices
}

\section{Onyiriuka A N, Francisca E N}

Department of Child Health, University of Benin Teaching Hospital and Department of Nursing Services, St Philomena Catholic Hospital, Benin City, Nigeria.

Correspondence address: Dr A.N. Onyiriuka, Department of Child Health, University of Benin Teaching Hospital, P.M.B 1111, Benin City, Nigeria

Email: alpndiony@yahoo.com,didiruka@gmail.com.

\begin{abstract}
Introduction: At home, mothers are usually the first to identify symptoms in their children and initiate treatment but there is paucity of information on these initial steps taken by these mothers. The objective of the study is to examine how mothers treat common childhood symptoms at home before presentation in the hospital.
\end{abstract}

Methods: A hospital-based cross-sectional study along with a structured interviewer-administered questionnaire was used for data collection from 307 consecutive mothers. Data obtained included their children's presenting symptoms, drugs administered, dosage regimen, source of the drugs, person who prescribed the drugs and storage of drugs. The axillary temperature of all the children were measured, using a mercury thermometer with the arm held firmly to the body.

Results: Fever either alone or in association with other symptoms was the commonest (75.6\%) presenting symptom. Among the 232 children reported as feverish by their mothers, $119(51.3 \%)$ had normal body temperature $\left(<37.5^{\circ} \mathrm{C}\right)$ while the remaining $113(48.7 \%)$ had elevated axillary temperature equal or greater than $37.5^{\circ} \mathrm{C}$. Analgesics, antimalarials and antibiotics were the three leading classes of drugs administered by the mothers, together accounting for $62.3 \%$ of all drugs. Antimalarials was the class of drug whose dosage regimen was most frequently incorrect, being correct in only $21.4 \%$ of cases. Mothers and patent medicine dealers accounted for $67.4 \%$ of all the prescriptions. The principal source of drugs was the patent medicine stores $(62.2 \%)$. Of the 307 mothers, 64 (20.8\%) administered left over drugs prescribed for a previous ailment. These drugs were stored mostly in closed cupboards and drawers $(67.2 \%$ of cases $)$ for a period of three to eight weeks (mean 5.2+0.8 weeks). The mothers had difficulty in correctly identifying fever with $51.3 \%$ of cases reported as feverish by their mothers having normal axillary temperature.

Conclusions: The present home-treatment practices by mothers regarding their children's symptoms is greatly deficient. Intervention aimed at improving the situation should include teaching mothers how to give oral drugs correctly, treat local infections, feed and give fluids during illnesses as well as ways of recognizing signs indicating immediate return to the health facility. Training of patent medicine dealers on the basics of drug action is also essential.

Keywords: Childhood symptoms, fever, home treatment, mother's action. 


\section{Introduction}

In general, it is the mothers rather than the fathers who first identify symptoms in their children and, subsequently, initiate some treatment, whether appropriate or inappropriate. Knowledge of these initial actions taken by the mother is important in that it can influence the duration, severity and eventual outcome of the particular illness. However, there is paucity of data on these initial steps taken by these mothers. ${ }^{1}$

One of the ways by which mothers respond to their children's symptoms is procurement and administration of drug(s) in the hope that it will alleviate their symptoms. Studies in Nigeria have shown that self-medication is common. For instance, a community survey by Enato et $\mathrm{al}^{2}$ in Nigeria, revealed that $82.0 \%$ of individuals obtained treatment for their ailment from informal health-care outlets such as patent and propriety medicine dealers/drug hawkers compared to $18.0 \%$ who received treatment from formal health-care facilities (Primary Health Centres and Hospitals). Similar finding has been reported from other African countries. ${ }^{3-6}$

Two potential problems associated with self-medication are inadequate- and over-dosing. Inadequate-dosing may lead to irrational drug use, and in the case of antimalarials/ antibiotics, development of resistance by the organisms. On the other hand, over-dosing is associated with the risk of drug toxicity.

In Nigeria ${ }^{2,7,8}$ and other African countries, ${ }^{3,9,10}$ procurement of drugs by mothers is very easy since they are sold without restriction by Patent Medicine Dealers (called "Chemists") in shops and drug hawkers in markets, motorparks, buses and even along the streets. This situation encourages the dangerous practice of self-medication in Nigeria. Ignorance and poverty are two factors known to play a role in preventing mothers from procuring the right medications in the correct quantities. ${ }^{1}$ Lack of complete picture of pattern of home-treatment practices as regards common childhood symptoms in our society constitutes a gap in our knowledge.

This study, therefore, sought to examine the pattern of materna ${ }^{1}$ procurement and administration of drugs to their children in response to common childhood symptoms prior to presentation in the hospital.

\section{Methods}

This cross-sectional study was conducted at the out-patient clinic of St Philomena Catholic Hospital (SPCH), Benin
City from 1st May to 31st July, 2009. The study population were all mothers who brought their children to the hospital with a history of drug administration at home prior to presentation in the hospital.

A structured interviewer-administered questionnaire was used for data collection from the mothers. The interviewers were the medical officers on duty at the hospital. The author reviewed method of completion of the questionnaire with each of the medical officers. The questionnaire sought information on maternal age and educational status, the children's presenting symptoms, drugs administered and their dosages, source of prescription, place of acquisition of drug and duration of treatment at home. The weights of the children were documented.

The axillary temperature of all the children was taken for two minutes, using a mercury thermometer and with the arm held firmly to the body. All the children had a complete physical examination and any clinical problem detected was treated as deemed fit. Comparison between fever reported by mothers and axillary temperature obtained during physical examination was performed.

Statistical analysis involved calculation of means, percentages and confidence intervals.

\section{Results}

Three hundred and seven consecutive mothers who met the inclusion criteria were recruited for the study following an informed consent. The maternal age ranged between 19-45 years with a mean of $28.3+3.2$ years as shown in Table 1 , approximately four out of every ten mothers had secondary education.

Table 1: Educational status of the respondents (mothers).

\begin{tabular}{|lll|}
\hline Educational status & $\begin{array}{l}\text { Number of } \\
\text { Respondents }\end{array}$ & Percentage \\
\hline No formal education & 12 & 3.9 \\
\hline Primary education & 90 & 29.3 \\
\hline Secondary education & 135 & 44.0 \\
\hline Tertiary education & 70 & 22.8 \\
\hline Total & 307 & 100 \\
\hline
\end{tabular}


Table 2: Distribution of clinical symptoms

\begin{tabular}{lll} 
Symptoms & Number of & \\
& Patients & Percentage \\
\hline Fever/Anorexia & 80 & 26.1 \\
\hline Fever & 63 & 20.5 \\
\hline Fever/Cough/Catarrh & 43 & 14.0 \\
\hline Cough/Catarrh/Anorexia & 37 & 12.0 \\
\hline Vomiting/Weakness & 24 & 7.8 \\
\hline Fever/Vomiting/Diarrhoa & 20 & 6.5 \\
\hline Fever/Cough/Catarrh/ & & \\
\hline Fast Breathing & 14 & 4.6 \\
\hline Fever/Convulsion & 12 & 3.9 \\
\hline Rash & 7 & 2.3 \\
\hline Abdominal pain & 7 & 2.3 \\
\hline Total & 307 & 100 \\
\hline
\end{tabular}

Table 2 showed that fever either alone or in association with other symptoms was the commonest presenting symptoms. Of the 307 children, 113 (36.8\%) had axillary temperature equal or greater than $37.5^{\circ} \mathrm{C}$. Out of 232 children reported as feverish by their mothers, 119 (51.3\%) had normal axillary temperature equal or greater than $37.5^{\circ} \mathrm{C}$. Duration of treatment of symptoms at home before presentation in the hospital ranged from one to seven days with a mean of $3.1+0.7$ days $(95 \% \mathrm{CI}=2.9-3.2)$.

Table 3: Pharmacological classification of prescribed drugs.

\begin{tabular}{|llc|}
\hline Class of drug & *Number of & \\
& Patients & Percentage \\
\hline Analgesics & 220 & 71.7 \\
\hline Antimalarials & 112 & 36.5 \\
\hline Antibiotics & 97 & 31.6 \\
\hline Vitamins & 73 & 23.8 \\
\hline Haematinics & 71 & 23.1 \\
\hline Antitussives & 37 & 12.1 \\
\hline Antiemetics & 13 & 4.2 \\
\hline Antidiarrhoeals & 12 & 3.9 \\
\hline Antihelminthics & 9 & 2.9 \\
\hline Others & 45 & 14.7 \\
\hline
\end{tabular}

*Two or more classes of drugs were prescribed for some individual patients.

As depicted in Table 3, the three leading classes of drugs administered at home by mothers were analgesics, antimalarials and antibiotics, together accounting for $62.3 \%$ of all drugs. As shown in Table 4, antimalarials was the commonest class of drug whose dosage was incorrect (78.6\% of cases). Correct dosage was administered only in $21.4 \%$ of cases (Table 3 ).

Table 4: Frequency of the correct dosage

\begin{tabular}{|llll|}
$\begin{array}{l}\text { Class of drug* } \begin{array}{l}\text { Correct dosage } \\
\text { dosage }\end{array} \\
\text { No (\%) }\end{array}$ & $\begin{array}{l}\text { Incorrect } \\
\text { No (\%) }\end{array}$ \\
\hline Analgesics & $\mathrm{n}=220$ & $130(59.1)$ & $90(40.9)$ \\
\hline Antimalarials & $\mathrm{n}=112$ & $24(21.4)$ & $88(78.6)$ \\
\hline Antibiotics & $\mathrm{n}=97$ & $40(41.3)$ & $57(58.8)$
\end{tabular}

* Current weight of patients were used in determining correctness (or otherwise) of dosage administered.

As shown in Table 5, the prescription pattern revealed that mothers and Patent Medicine Dealers together accounted for $84.4 \%$ of the prescriptions used for treatment at home.

Table 5: Source of prescription

\begin{tabular}{lll} 
Source & Frequency & Percentage \\
\hline Mother & 126 & 41.0 \\
\hline Patent medicine dealer & 81 & 26.4 \\
\hline Doctor & 50 & 16.3 \\
\hline Father & 21 & 6.9 \\
\hline Nurse & 16 & 5.2 \\
\hline Neighbours/Relatives/ & & \\
\hline Friends & 9 & 2.9 \\
Pharmacists & 4 & 1.3 \\
\hline Total & 307 & 100
\end{tabular}


Table 6: Distribution on source of drugs

\begin{tabular}{lll} 
Source & Frequency & Percentage \\
\hline Patent medicine store & 191 & 62.2 \\
Maternity home/ & & \\
Health centre/Clinic & 48 & 15.7 \\
Hospital & 39 & 12.7 \\
Drug hawkers & 17 & 5.5 \\
Pharmacy store & 12 & 3.9 \\
Total & 307 & 100
\end{tabular}

Table 6 showed that the principal source of drug was the patent medicine store $(79.2 \%)$. Other sources of drugs are shown in rank order in Table 6 . Of the 307 mothers, $64(20.8 \%)$ administered left over drugs obtained for a previous ailment. These drugs were stored for a period of three to eight weeks (mean 5.2 $\neg+0.8$ weeks) under poor conditions. The drugs were either stored in closed cupboards or drawers $(67.2 \%)$, open shelves or on top of a table $(22.4 \%)$ or tied in polythene bags $(10.4 \%)$.

Table 7: Fever reported by mothers compared to measured axillary temperature

Mother's Children's axillary $\quad$ Total
complaints temperature $\left({ }^{\circ} \mathrm{C}\right)$

$$
\mathrm{n}=307
$$

\begin{tabular}{|c|c|c|c|}
\hline & \multicolumn{3}{|l|}{$<37.5$ (fever } \\
\hline & \multirow[t]{2}{*}{ absent) } & \multirow{2}{*}{\multicolumn{2}{|c|}{$\begin{array}{l}>37.5 \text { (fever } \\
\text { present) }\end{array}$}} \\
\hline & & & \\
\hline & No $(\%)$ & No $(\%)$ & No \\
\hline & $(\%)$ & $(\%)$ & \\
\hline \multicolumn{4}{|l|}{ Sick and } \\
\hline feverish & $119(51.3)$ & $113(48.7)$ & $232(75.6)$ \\
\hline \multicolumn{4}{|c|}{ Sick but not } \\
\hline feverish & $49(65.3)$ & $26(34.7)$ & $75(24.4)$ \\
\hline
\end{tabular}

As depicted in Table 7, slightly over half of the mothers had difficulty identifying fever correctly.

\section{Discussion}

Fever either alone or in combination with respiratory symptoms such as cough and catarrh was the commonest presenting symptom, accounting for the frequent use of analgesics, antimalarials and antibiotics observed in the present study. Similar observation was reported by
Ezechukwu et $\mathrm{a}^{18}$ in their study in a private clinic in Nnewi, Nigeria. In a community survey in Jesse, Nigeria, these classes of drugs were also the most frequently encountered in the households studied. ${ }^{2}$ This pattern of drug class usage suggests that the mothers assumed that fever was either due to malaria or infections.

Our data show that incorrect dosage was most frequent with antimalarials (78.6\% of occasions). Other investigators have also reported high frequency of incorrect dosage with antimalarials ${ }^{4,7,8}$ even in academic communities. ${ }^{11}$ The potential consequences include prolonged suffering to patient, occurrence of complications, hospitalization and ultimately, increased cost of treatment. In Nigeria, several studies have shown that financial constraint is leading cause of discharge of hospitalized children against medical advice. ${ }^{12,13}$ Furthermore, $20.8 \%$ of our mothers administered left over improperly stored drugs obtained for a previous ailment. Similar observation has been reported by other investigators ${ }^{2,7,10}$ With regard to this practice, two potential problems are that the medicines are likely to lose their potencies and may even degrade into toxic products. Consumption of the toxic products may result in serious deleterious effects. For instance, outdated tetracycline capsules is known to cause Fanconi syndrome ${ }^{14}$ Although medicines play a pivotal role in effective health care delivery, its curative properties depend largely on how they are used. They must be prescribed or purchased by informed or trained person, be appropriate for the complaints and be taken in the right dosage regimen at the right time. ${ }^{15}$ In the present study, mothers and patent medicine dealers together accounted for majority (67.4\%) of the "prescriptions" for home treatment. This observation is worrisome in that it reflects the great danger these children are exposed to from inappropriate treatment and possible drug toxicities from over-dosage, since both the mother and the patent medicine dealers are not trained to appreciate the contraindications and side-effects of the drugs they administer. The principal role of patent medicine dealers in our informal healthcare outlets is further highlighted by the fact that $62.2 \%$ of our mothers obtained the drugs they administered to their children from patent medicine stores. Other African studies $^{16-18}$ have reported a similar trend. Some of these medicine stores are unauthorized to stock the drugs; a circumstance that makes sourcing of genuine drugs less likely, resulting in increased probability of these children receiving fake and adulterated drugs.

In this study, although fever was the most frequently reported symptom by mothers, a comparison of the history of fever and the measured axillary temperature suggested that the mothers have difficulty in correctly identifying fever. Other 
investigators have reported a similar finding. ${ }^{19}$ This is in contrast to a report from a Ghanaian study which indicated that fever was often correctly identified by mothers. ${ }^{20}$ Two possible explanation for the discordance between mothers' observations and the measured axillary temperature found in this study are (i) the fever may have disappeared between the time it was detected by the mother at home and the time of measurement of the body temperature in the hospital; (ii) the fever may just have developed and so was not detected by the mother. This second possibility portends a serious danger for the child in that treatment and/or appropriate medical consultation will be delayed.

\section{Conclusions}

There were great deficiencies in the care received at home by these children for their symptoms. Intervention strategies to address the situation should include training of Patent Medicine Dealers on the basics of drug actions and educating mothers on how to give oral drugs correctly, feed and give fluids to their children during illnesses, and treat local infections. This health education must emphasize to the mothers ways of recognizing danger signs that indicate that the child should return immediately to the health facility.

Conflict of interest: The authors declare that they have no conflict of interests.

\section{References}

1. Erinosho AO. Health Sociology for Universities, Colleges, Health-related institutions. Ibadan, Sam Bookman Educational and Communication Services, 1998: 39-54.

2. Enato EFO, Aghomo OE, Oparah CA, Odili UV, Etaghene BE. Drug utilization in a rural Nigerian Community. J Med Biomed Res 2003; 2 (2): 15-21.

3. Ahorlu CK, Afari EA, Dunjo SK. Malaria related belief and behaviour in Southern Ghana. Trop Med Inter Hlth 1997; 2(5):488-499.

4. Munguiti KJ. Community perception and treatment seeking for malaria in Baringo district, Kenya. East Afr Med J. 1998; 75 (2): 687-691.

5. Foster S. Treatment of malaria outside the formal health services. J Trop Med Hyg 1995; 98: 29-34.

6. Djimde A, Plowe CV, Dicko A, Wellems TE, Doumbo O. Use of antimalarial drugs in Mali: Policy versus reality. Am J Trop Med Hyg 1998; 59 (3): 376-379.

7. Ibeh CC, Ekejindu IM, Ibeh NC, Shu EN, Chukwuka JO. The pattern of home treatment of malara in under-fives in South Eastern Nigeria.
Afr J. Med Sci 2005; 34: 71-75.

8. Ezechukwu CC, Egbuonu I, Chukwuka JO Drug treatment of common childhood symptoms in Nnewi: what mothers do? Niger J Clin Pract 2005; 8 (1): 1-3.

9. Julvez J. Sale of chloroquine in the street of Niamey, Niger. Bull Soc Pathol Exot 1999; 92 (1): 31-32.

10. Kiyingi KS, Launo JAK. Drugs in the home: danger and waste. World Health Forum 1993; 14: 381-384.

11. Wagbatsoma VA, Obomighie JE, Nwokike NH. Home management of malaria in an academic communityUniversity of Benin, Benin City, Nigeria. J Med Biomed Res 2004; 3 (1): 73-80.

12. Ibekwe RC, Muoneke VU, Nnebe-Agumadu UH, Amadife MA. Factors influencing discharge against medical advice among paediatric patients in Abakaliki, Southeastern Nigeria. J Trop Paediatr 2009; 55(1): 3941 .

13. Okoromah CN, Egri-Okwaji MT. Profile of and control measures for paediatric discharge against medical advice. Niger Postgrad Med J 2004; 11(1): 21 - 25.

14. Chambers HF. Chloramphenicol, Tetracyclines, Macrolides, Clindamycin and Streptogramins In: Katzung BG (ed). Basic and Clinical Pharmacology 9th edn. Singapore, McGraw Hill Companies (Asia), 2004; 754-763.

15. Holford NHG. Pharmacokinetics and Phamacodynamics: Rational dosing and time course of drug action. In: Katzung BG (ed). Basic and Clinical Pharmacology 9th edn. Singapore McGraw Hill, 2004; 34-50.

16. Nshakira N, Krietensen M, Ssali F, Whyte SR. Appropriate treatment of malaria? Use of antimalarial drugs for children's fevers in district medical units, drugs shops and homes in eastern Uganda. Trop Med Int Health 2002; 7(4): 309 - 316.

17. Ruebush TK, Kem MK, Campbell CL, Oloo AJ. Self treatment of malaria in rural area of Kenya. J Health Soc Behaviour 1989; 30: 421-435.

18. Mwenesi H, Harpharn T, Snow RW. Child malaria treatment among mothers in Kenya. Soc Sci Med 1995; 40: 1271-1277.

19. Diallo AB, De Serres G, Beavogui AH, Lapointe C, Veins P. Home care of malaria infected children of less than 5 years of age in rural area of the Republic of Guinea. Bull World Health Org 2001; 79 (1): 28-32.

20. Abuaku BK, Koram KA, Binka FN. Antimalarial drug use among caregivers in Ghana. Afr Health Sci 2004; 4(3): 171-177. 